\title{
MONUMENTO À ANITA E GIUSEPPE GARIBALDI -
} DIAGNÓSTICO E TRATAMENTO

\author{
Verônica Di Benedetti', Luiz Antônio Bolcato Custódio², Clóvis Gonzatti
}

1 - Arquiteta e Urbanista, Profissional Liberal;

2 - Arquiteto, Professor Centro Universitário Uniritter, Coordenador Memória Cultural Secretaria da Cultura de Porto Alegre 3 - Eng. de Minas, Professor, DEMIPE - IGEO - UFRGS, Porto Alegre veronicadibene@gmail.com

\begin{abstract}
Resumo: Por mais de um século o monumento à Anita e Giuseppe Garibaldi, obra de Filadelfo Simi, escultor fiorentino, executada em mármore de Carrara, encontra-se exposto a céu aberto na Praça Garibaldi, em Porto Alegre. Seu precário estado de conservação levou a Coordenação da Memória Cultural a contratar, em 2014, serviços técnicos especializados para desenvolvimento de projeto e realização de intervenções para sua conservação. Partindo da premissa de que é necessário compreender a obra para que um projeto de recuperação tenha êxito, foram realizados levantamentos do material constituinte, ensaios de caracterização tecnológica e medições de índices físicos e geofísicos que forneceram dados para o diagnóstico. Buscava-se entender as causas e efeitos provocados pela exposição ao tempo, assim como as sucessivas ações humanas que, incidindo sobre o monumento, interferiram em seu estado de conservação, na matéria e, como consequência em sua imagem. Da mesma forma, procurou-se definir diretrizes e critérios de intervenção que foram utilizados na primeira etapa realizada.
\end{abstract}

Palavras Chave: mármore, caracterização, diagnóstico

Abstract: MONUMENT TO ANITA AND GIUSEPPE GARIBALDI: DIAGNOSIS AND TREATMENT. For over a century the Monument to Anita and Giuseppe Garibaldi, a work of Filadelfo Simi, a Florentine sculptor, executed in Carrara marble, is exposed to open air at Garibaldi Square, in Porto Alegre. Its precarious state of conservation led the department in charge Coordination of Cultural Memory to contract in 2014 specialized technical services for project development and interventions for its conservation. Considering the premise that it is necessary to understand the work for a recovery project to succeed, assessments of the constituent materials were conducted, including technological characterization tests and measurements of physical and geophysical indexes that provided data for the diagnosis. These sought to understand the causes and effects of weather exposure as well as successive human actions, which interfered in its conservation, and as a result on its appearance. Also, we define guidelines and intervention criteria that were used in the first step performed.

Keywords: marble, characterization, diagnosis

\section{INTRODUÇÃO}

A problemática da conservação de monumentos executados em rocha calcária e localizados em áreas externas é bastante conhecida. O monumento à Anita e Giuseppe Garibaldi é mais um caso a ser analisado. Concebido em mármore de Carrara foi encomendado pela colônia Italiana homenageando os heróis da Revolução Farroupilha. A escultura foi instalada na Praça Garibaldi em 1912 onde permanece sob ação dos mais variados agentes de degradação, processos de intemperismo químico e biológico, somados a diferentes atos de vandalismo. Em função desses fatores a obra de arte exigia a atenção de profissionais especializados, capazes de identificá-los e com capacidade para executar medidas conservativas.

Ao analisar o monumento, foram considerados três aspectos: o ambiente no qual está inserido, as questões intrínsecas ao material e ações antrópicas. Investigar os mecanismos de degradação atuantes na rocha metamórfica constituinte, suas manifestações patológicas, o comportamento de seus minerais frente aos agentes intempéricos e a interação com o ambiente no qual está inserido, foi primordial para buscar soluções para conservar esse patrimônio. Para isso foi proposto uma ação multidisciplinar a qual explorou os recursos tecnológicos existentes na área da geologia,

doi: $10.18285 /$ geonomos.v24i2.882 juntamente com o conhecimento técnico por parte do responsável técnico, o arquiteto restaurador. Nessa ação foram realizados ensaios para caracterização mineralógica, física e geofísica da obra.

A conservação do monumento em seu local original exigiu conhecimento dos agentes patogênicos e o entendimento das alterações ocorridas no material. O controle, através de monitoramento das variáveis, aponta como sendo o melhor caminho a ser seguido. Porto Alegre possui em seu acervo escultórico outros monumentos construídos com material de mesma natureza instalados entre o final do século XIX e início do século $X X$, sendo estas as obras de arte pública mais antigas da cidade; todas elas com admirável valor artístico e em delicado estado de conservação. Este trabalho busca contribuir para a formulação de uma metodologia para intervenção e conservação em monumentos desta natureza.

\subsection{Metodologia}

Inicialmente, foram realizados levantamentos cadastrais referentes à técnica construtiva empregada, o material constituinte e a localização do monumento. Em seguida foram observados os mecanismos de degradação atuantes e as patologias resultantes. Com o intuito de determinar o grau de alteração do material constituinte, foram selecionados ensaios destrutivos e não destrutivos. 
Para a realização dos ensaios duas amostras foram selecionadas: a primeira coletada em parte do embasamento, constituída de um fragmento de mão solto (RM-1) e a segunda, (RS-1) coletada no mercado de varejo e identificada como mármore de Carrara. No Laboratório de Mineralogia e Petrologia do Instituto de Geociências da UFRGS os ensaios realizados consistiram de análise petrográfica $e$ determinação dos índices físicos nas duas amostras (RM-1 e RS-1). Os trabalhos in situ, consistiram na realização de ensaios para a determinação da velocidade de propagação de ondas ultrassônicas. Reunidos os levantamentos e relatórios das análises os dados foram confrontados para avaliação das patologias levando ao diagnóstico que foi seguido por diretrizes para intervenção conservativa.

\section{LEVANTAMENTO CADASTRAL}

A análise histórica do objeto de estudo identificou sumariamente o local da execução, o período e a técnica utilizada. O monumento foi esculpido em Florença, Itália, entre 1908 a 1912, pelo autor o escultor Filadelfo Simi, que utilizou a técnica de cinzelamento com acabamento denominado grafiatto. $\mathrm{O}$ monumento em linguagem clássica foi estruturado em três partes, duas composições formando a base e na parte superior foi instalado um conjunto escultórico formado por uma figura masculina em pé (Giuseppe Garibaldi) e uma feminina (Anita Garibaldi) ajoelhada junto a um canhão. As peças foram transportadas de navio tendo como destino a então Praça Concórdia, construída a partir de 1873, localizada originalmente nas proximidades do Arroio Dilúvio, tendo sido posteriormente deslocado para a localização atual. Atualmente, a praça denomina-se Garibaldi e a área encontra-se entre grandes avenidas com intenso fluxo de veículos. Como decorrência recebe grande interferência ambiental. A vegetação plantada no entorno do monumento se desenvolveu constituindo uma cobertura vegetal significativa com a inserção de paineiras, ipês, canafístulas e palmeiras da Califórnia que abrigam e alimentam a avifauna.

\subsection{Mecanismos de degradação}

Durante análise do estado de conservação foram observados diferentes mecanismos de degradação que levaram o monumento ao delicado estado de preservação. Os principais agentes responsáveis por esta degradação foram; ação de poluentes atmosféricos; microclima; organismos biológicos e ação antrópica. Citamos ainda fatores intrínsecos ao material rochoso. Estes favoreceram o aparecimento das seguintes patologias: dissolução do material, alteração cromática, destacamento, fraturamento, crosta negra e pátina biológica.
Para um maior entendimento da rocha que constitui o monumento, e referente às patologias que nele se instauraram é importante conhecer suas propriedades físicas, mecânicas e características mineralógicas. A avaliação dessas características e dos problemas constatados foi efetuada pela análise das variantes que provocaram as manifestações patológicas, bem como, pela interpretação dos ensaios tecnológicos.

Denominada comercialmente como Mármore de Carrara, a rocha metamórfica constituinte do monumento em estudo apresenta cor branca, estrutura maciça e textura granoblástica equigranular poligonal média. Petrograficamente corresponde a um mármore calcítico apresentando $100 \%$ do mineral Calcita $\left(\mathrm{CaCO}_{3}\right)$. Esse mineral apresenta baixa estabilidade em condições intempéricas, principalmente em presença de água.

A localização da praça, em ambiente urbano com alto tráfego de veículos, confere elevados níveis de poluição atmosférica. $O$ dióxido de carbono presente no ar em contato com a água das chuvas, ou mesmo com a umidade do ar, propicia a formação de compostos de caráter ácido que ao reagirem com a calcita, provocam a solubilização do mármore, lixiviando sua superfície. A calcita à temperatura ambiente é pouco solúvel na água pura $(0,014 \mathrm{~g} / \mathrm{l})$, mas quando em contato com anidrida carbônica dissolvida em água transforma-se em bicarbonato de cálcio que é extremamente solúvel (1 g/l) (LAZZARINI\&TABASSO, 1986, p.23).

Devido à intensa arborização do local, o ambiente no qual o Monumento está inserido possui um microclima propício à manutenção da alta umidade do ar, característica da cidade de Porto Alegre. Ao longo da existência da obra no local, devemos destacar ainda a presença de um espelho d'água, localizado junto ao Monumento assim como a proximidade do arroio Dilúvio com curso natural próximo à praça. Além do ataque químico resultante do ciclo de vida dos organismos, o mármore sofre ainda com a ação do material particulado (hidrocarbonetos) transportado pelo vento, servindo de alimento aos organismos vivos, pois o carbono é indispensável a todos os microorganismos porque faz parte de quase todos os polímeros que compõem sua estrutura celular e suas enzimas.

Somado aos agentes de intemperismo acima citados, outro importante fator a ser considerado na deterioração do Monumento, é a ação antrópica. Alvo de vandalismo sistemático ou de manifestações políticas, o monumento à Anita e Giuseppe Garibaldi foi pichado inúmeras vezes e suas partes mais frágeis arrancadas. No processo de análise visual foram identificados os tipos de materiais presentes no monumento: látex PVA, tintas automotivas 
(spray), óleo, lápis grafite, giz de cera, cola de cartazes, cartazes e graxa de sapato.

\subsection{Patologias}

Afetados por ação do intemperismo químico e biológico a rocha sofre o desgaste natural dos minerais que a compõem. Com isso observa-se a mudança da textura superficial do monumento decorrente da dissolução dos minerais, a alteração da cor, a presença de crosta negra e de pátina biológica.

A dissolução da rocha está diretamente ligada a sua composição mineralógica e ao ambiente em que se encontra. Essencialmente de composição carbonática, o mármore constituinte do monumento está inserido em um ambiente onde a presença de água e de poluentes atmosféricos é uma constante. Nota-se que a superfície do conjunto escultórico está bastante alterada, encontrando-se com superfície áspera e em alguns pontos bastante rugosa.

Para verificação do grau de intemperismo foram realizados ensaios físicos como de densidade aparente natural $\left(1,89 \mathrm{~g} / \mathrm{cm}^{3}\right)$, de absorção de água $\left(\alpha_{a}=9,5 \%\right)$ e de porosidade aparente $\left(\eta_{a}=18,1\right)$.

Quando se trata de obras de arte, modificações na coloração da rocha comprometem a imagem da peça não só quanto a sua leitura estética, mas principalmente porque indica a presença de problemas de conservação. 0 monumento apresentava colorações variadas decorrentes de patologias como crosta negra e biofilme. Precipitações de sulfato de cálcio dihidratado (gipsita) conforme equação 1, alteram a cor inicialmente branca do mármore para tons de cinza claro. Segundo Lorenzo Lazzarini (1981, p. 24) a principal causa de deterioração ligada à presença de crosta negra é o alto teor de gipsita, o qual participa ativamente no ciclo de intemperismo químico de solubilização $(2,4 \mathrm{~g} / \mathrm{l}$ a 20 C) e a cristalização.

As dissoluções migram para a superfície e se depositam em áreas onde águas de lavagem não atingem. Este processo gera tensões mecânicas localizadas, uma vez que as deposições tornam-se mais resistentes que o próprio substrato fragilizado pelas dissoluções.

Locais onde a manutenção da umidade é uma constante há a presença de biofilme. Esta ocorrência favorece a dissolução dos minerais, aumentando a porosidade da rocha devido à extração de nutrientes dos minerais. Assim como a umidade que favorece a proliferação de microflora, a presença desta também aumenta a retenção de água na superfície da rocha devido ao manto que ali forma. Sobre este substrato poroso e sensível ao meio em que se encontra, temos o agravante das intervenções humanas. Grande quantidade de pichações com tintas das mais diversas naturezas também agravam a conservação do monumento.

\subsection{Ensaios de Caracterização Física e} Petrográfica da Rocha Constituinte do Monumento

Os trabalhos de caracterização física in situ consistiram na determinação da velocidade de ondas ultrassônicas (onda P) utilizando um equipamento portátil marca PROCEQ, equipado com geofones de $500 \mathrm{kHz}$ e os procedimentos baseados na norma ASTM D2845. Trata-se de uma técnica de ensaio não-destrutiva, que permite avaliar o grau de sanidade da rocha quando comparada com determinações sobre a mesma rocha na condição sã. Na prática, quanto mais sã e íntegra estiver a rocha, maior será a velocidade de propagação das ondas. Os resultados fornecem bons indicativos sobre o estado de degradação (porosidade, grau de fissuração) do material. A técnica utilizada foi a indireta, em duas linhas localizadas na base e nomeio do pedestal do monumento. Em cada uma das linhas foram realizadas entre 3 e 4 determinações de velocidade, nas seguintes configurações de distâncias entre os geofones:

- linha na base: $0-10-20 \mathrm{~cm}, 0-20-40 \mathrm{~cm}$ e $0-30$ $60 \mathrm{~cm}$;

- linha no meio do pedestal: 0-5-10cm, 0-10$20 \mathrm{~cm}, 0-20-40 \mathrm{~cm}$ e $0-40-80 \mathrm{~cm}$.

Os valores médios variaram entre $4,1 \mathrm{~km} / \mathrm{s}$ (no meio do pedestal) e $4,3 \mathrm{~km} / \mathrm{s}$ (na base do pedestal).

Em laboratório, além da determinação da velocidade de propagação de ondas em uma amostra do mármore na condição sã (RS-1), foram realizadas análises petrográficas e determinações de densidade tanto em amostra coletada do monumento (RM-1), como na rocha sã (RS-1). A Figura1 mostra $\mathrm{o}$ equipamento usado nas determinações da velocidade de ondas em laboratório.

As análises petrográficas nas duas amostras foram realizadas em superfície cortada, utilizando lupa petrográfica, ácido clorídrico e uma solução de Vermelho de Alizarina para determinação da composição do tipo de carbonato, que é o principal mineral da rocha. No teste com a solução de Vermelho de Alizarina, a coloração rosa observada em toda a superfície exposta à solução indicou a presença de mineral calcita $\left(\mathrm{CaCO}_{3}\right)$. Vale dizer que esta composição é reativa aos ácidos presentes na água da chuva, principalmente, ao ácido carbônico $\left(\mathrm{H}_{2} \mathrm{CO}_{3}\right)$, o qual se constitui no principal agente natural de intemperismo da rocha. A Tabela 1 
apresenta a síntese dos resultados de caracterização obtidos in situ e em laboratório.

Petrograficamente as amostras apresentam semelhança, podendo ser caracterizadas litologicamente como sendo mármores calcíticos.

Os resultados de laboratório e in situ indicam claramente que a amostra procedente do monumento (RM-1) possui parâmetros físicos relativamente diferentes da amostra de rocha sã (RS-1). Essa variação está associada essencialmente aos processos intempéricos atuantes sobre o monumento ao longo do tempo, enquanto que a rocha sã não foi submetida a estes processos de alteração.

Quantitativamente, comparada com a rocha sã a amostra do monumento perder cerca de $30 \%$ na densidade. Esse comportamento é corroborado pela redução na velocidade das ondas ultrassônicas, quando comparadas as velocidades in situ (no monumento) e na rocha sã. A redução da velocidade da rocha in situ é também da ordem de 30\% em relação a rocha sã.

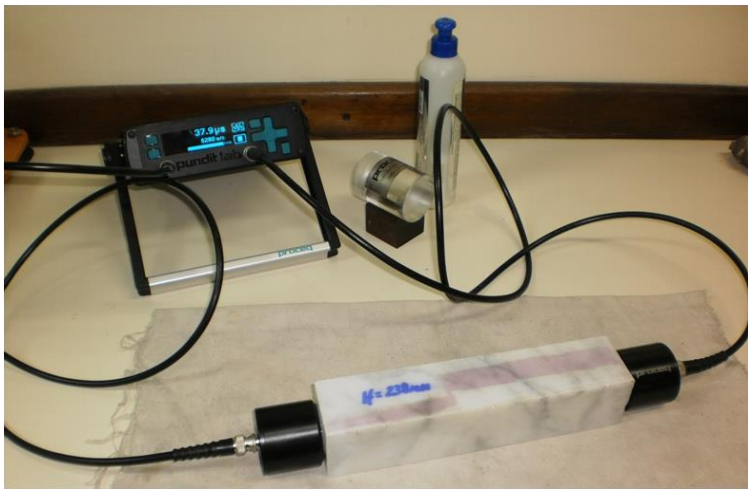

Figura 1. Determinação da velocidade de propagação de ondas $P$ na amostra de rocha sã em laboratório (Fonte: Clóvis Gonzatti).

Tabela 1. Resultados das determinações da mineralogia e índices físicos nas amostras de rocha ensaiadas.

\begin{tabular}{|c|c|c|c|c|}
\hline $\begin{array}{l}\text { Identificação } \\
\text { da Amostra }\end{array}$ & $\begin{array}{l}\text { Síntese da } \\
\text { Análise } \\
\text { Petrográfica }\end{array}$ & $\begin{array}{c}\text { Densidade } \\
\left(\mathrm{g} / \mathrm{cm}^{3}\right)\end{array}$ & $\begin{array}{c}\text { Velocidade } \\
\text { da Onda } \\
\mathrm{P}(\mathrm{km} / \mathrm{s})\end{array}$ & Observações \\
\hline \multirow[t]{2}{*}{$\begin{array}{c}\text { Rocha do } \\
\text { monumento } \\
(\mathrm{RM}-1)\end{array}$} & \multirow{4}{*}{$\begin{array}{l}\text { - Tipo litológico: } \\
\text { mármore } \\
\text { calcítico } \\
\text { - Estrutura: } \\
\text { maciça } \\
\text { - Textura: } \\
\text { granoblástica } \\
\text { equigranular } \\
\text { poligonal } \\
\text { média } \\
\text { - Composição } \\
\text { mineralógica: } \\
\text { Calcita 100\% }\end{array}$} & \multirow[t]{2}{*}{1,89} & 4,1 & $\begin{array}{l}\text { Linha no meio } \\
\text { do pedestal. }\end{array}$ \\
\hline & & & 4,3 & $\begin{array}{l}\text { Linha na base } \\
\text { do pedestal. }\end{array}$ \\
\hline \multirow[t]{2}{*}{$\begin{array}{c}\text { Rocha Sã } \\
\text { (RS-1) }\end{array}$} & & \multirow[t]{2}{*}{2,73} & 6,1 & $\begin{array}{c}\text { Direção da } \\
\text { largura da } \\
\text { amostra. }\end{array}$ \\
\hline & & & 6,3 & $\begin{array}{l}\text { Direção do } \\
\text { comprimento } \\
\text { da amostra. }\end{array}$ \\
\hline
\end{tabular}

\section{INTERVENÇÕES}

Após análise do diagnóstico foram determinadas como diretrizes de intervenção os processos de limpeza, consolidação e proteção.

Inicialmente, foram realizados testes de limpeza química a fim de determinar o método adequado para remoção dos diversos tipos de tinta da rocha. Foram testados, através do uso de suobe, solventes do tipo acetona (penetrantes e com baixo poder de retenção) e solventes derivados de nitro (muito penetrantes e poder de penetração não definido). Ambos os solventes testados mostraram resultado insatisfatório. A elevada porosidade aparente da rocha ( $\eta_{a} 18,1 \%$ ) contribuiu para a penetração e ancoragem dos mais diversos tipos de materiais utilizados para pichação. Os materiais que apresentaram a maior ancoragem foram a graxa de sapato e a cola utilizada para fixação de cartazes. Nenhum teste químico mostrou resultado satisfatório. Para limpeza das sujidades orgânicas foi utilizado, após testes de concentração, solução de sal de amônio quaternário (3\%) mostrando bons resultados na desinfestação da microflora. Também foi utilizada para teste de limpeza do monumento a solução denominada AB57. a qual contém bicarbonato de amônio, bicarbonato de sódio, desogen, carboximetil celulose e E.D.T.A.. Devido ao grau de alterabilidade da rocha, esta solução foi reprovada por atacar os cristais de calcita. Para remoção dos agentes patogênicos como as pichações, deposições e crosta negra foi empregada a limpeza física, através de microjateamento com material inerte (carbonato dureza 3) e pressão controlada. Apresentando alteração quanto a porosidade e perda de massa, a rocha necessitou passar por processos de consolidação a fim de desacelerar o processo de alteração intempérica e aumentar sua resistência mecânica. Para tal foi empregado solução de silicato de etila $28 \%$ aplicado por pincelamento. Optou-se por não aplicar um segundo protetivo uma vez que o próprio silicato de etila possui características protetivas quanto a hidrorrepelência, porém permitindo a troca de vapores necessárias a conservação da rocha.

\section{CONSIDERAÇÕES FINAIS}

O trabalho desenvolvido no monumento à Anita e Giuseppe Garibaldi foi considerado como uma medida de intervenção conservativa. Inicialmente, sob análise visual, pensou se tratar de um problema predominantemente estético. No entanto, após as análises realizadas foi constatado considerável perda de material e elevados índices de absorção da rocha $(18,1 \%)$.

A deterioração apresentada resultou da interação entre a rocha e os agentes intempéricos, 
resultando na dissolução dos minerais com o consequente aumento da porosidade superficial do monumento. A solubilização da calcita frente à água de caráter ácido levou a alteração dos minerais e conseqüente desagregação dos minerais constituintes.

A elevada porosidade decorrente da dissolução dos carbonatos propiciam a manutenção da umidade na obra, facilitando a fixação e o desenvolvimento de microflora, conferindo à obra pátinas biológicas.

As intervenções ocorridas, como medidas conservativas, mostraram-se satisfatórias. Conforme é possível verificar na figura 2, passados dois anos ainda não são observadas patologias como biofilme, crostas ou mesmo pátinas de deposição superficial. No entanto, o monumento ainda sofre com ações de vandalismo. Acreditamos que para salvaguardar a longo prazo tão importante obra de arte, será necessário efetuar uma investigação mais apurada de todas as variantes envolvidas e um monitoramento permanente dos processos de degradação da peça.

Os ensaios realizados foram fundamentais para uma melhor compreensão da alterabilidade da rocha, direcionando assim as intervenções realizadas. Isto vem reforçar a importância da análise geológica dos materiais como parte das ações de conservação e restauração dos elementos pétreos.

\section{REFERÊNCIAS BIBLIOGRÁFICAS}

American Society for Testing and Materials. ASTM-D 2845 Standard Test Method for Laboratory Determination of Pulse Velocities and Ultrasonic Elastic Constants of Rock.

LAZZARINI, L. \& TABASSO, M.L. 1986. II Restauro della Pietra. Padova, CEDAM, 315p.

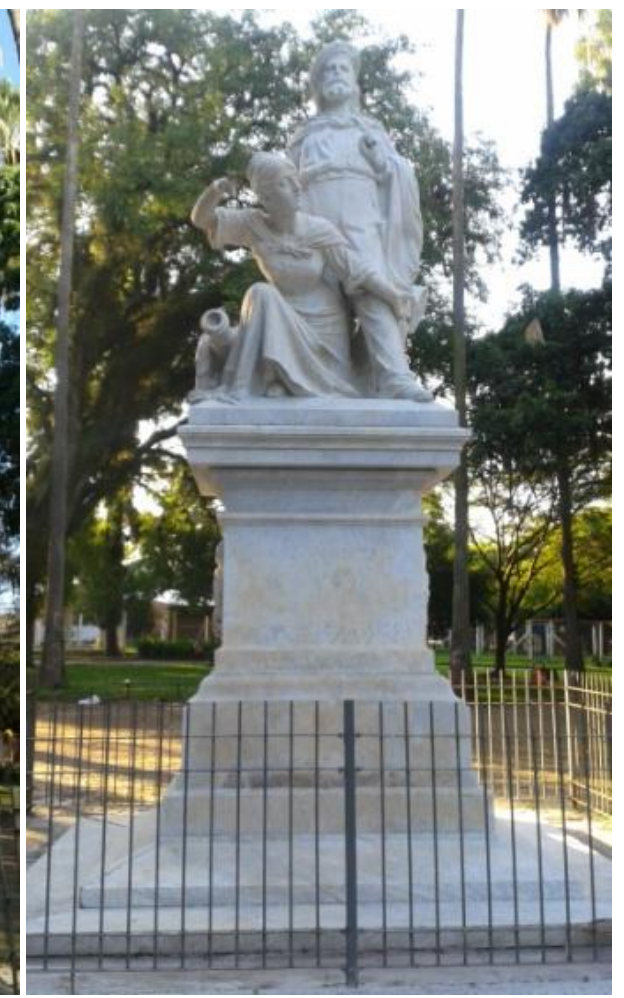

Figura 2. Monumento à Anita e Giuseppe Garibaldi antes e depois da intervenção - Orientação solar oeste (Fonte: Verônica Di Benedetti).

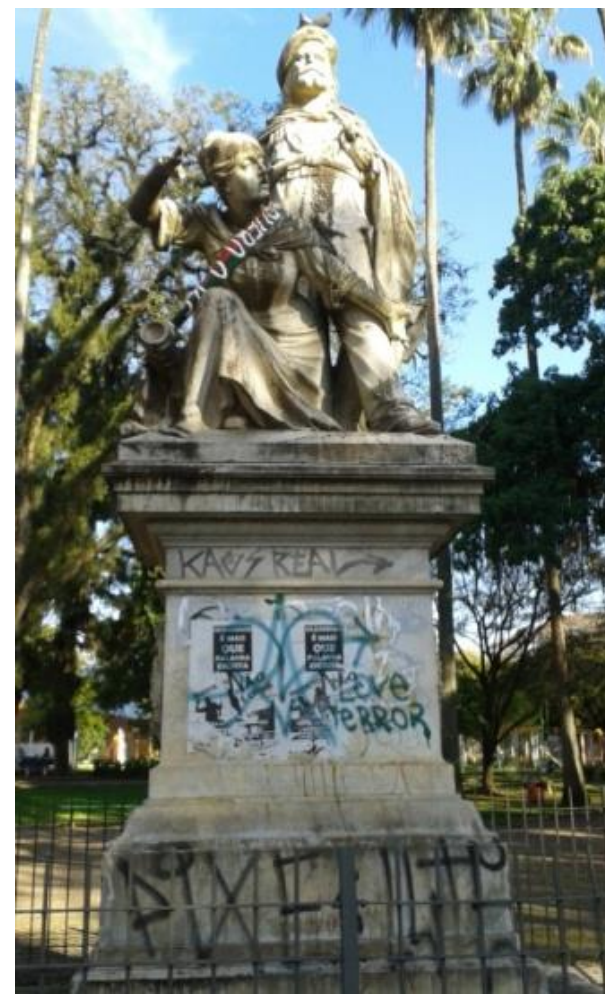

Figura 2. Monumento á Anita e Giuseppe Garibaldi antes edepois da intervenço - Orientacáo solar oeste (Fonte: Veronica DiBenedetti). 